\title{
Both JNK and apoptosis pathways regulate growth and terminalia rotation during Drosophila genital disc development
}

\author{
SERGIO BENITEZ, CLAUDIA SOSA, NICOLÁS TOMASINI and ANA MACÍAS* \\ Laboratorio "Genética del Desarrollo", Facultad de Ciencias Exactas Físicas y Naturales de la Universidad \\ Nacional de Córdoba, Córdoba, Argentina
}

\begin{abstract}
Apoptosis is necessary for the regulation of growth during development, but the precise details of this regulation have not been completely characterized. In this study, we used the Drosophila genital disc as a model to analyze the contribution of apoptosis to growth regulation. We studied the expression or activity of several elements of the apoptotic death pathway such as Drosophila inhibitor of apoptosis 1, caspases, the apoptotic genes reaper (rpr) and head involution defective, as well as elements of the Jun- $\mathrm{NH}_{2}$-terminal kinase (JNK) pathway. We found that the JNK pathway is active in a dynamic, asymmetric and genitalia-specific manner. Apoptosis, as measured in terms of the expression of a variety of apoptotic molecules, occurs in a JNK-dependent and -independent manner and was detected among engrailed (en) expressing cells. JNK regulation of apoptotic genes is necessary to control growth in both sexes and rotation in males; this regulatory role is necessary to execute en ${ }^{+}$cell death and to activate expression of $r p r$ in these cells. rpr is up-regulated at antero-posterior borders, and this expression appears to be of particular importance in the control of growth, since the balance between cell proliferation and death in those regions appears to depend on the equilibrium between pro- and anti-apoptotic factors at a cellular level.
\end{abstract}

KEY WORDS: genital disc, JNK, apoptosis, reaper, Drosophila

\section{Introduction}

The genital disc is unique among imaginal discs in that it is the only unpaired disc with bilateral symmetry. However, its morphology and growth characteristics differ in males and females. The genital disc arises from the invagination and fusion of ventral cells from the eighth (A8), ninth (A9) and tenth (A10) abdominal segments (reviewed in Sánchez and Guerrero, 2001; Estrada et al., 2003, Chen et al., 2005). Although originating from the same ventral posterior segments, the precursor cells develop into sexually dimorphic structures, in accordance with the sex-determination genes. The female genitalia with their several organs in females derive from $A 8$ cells, while, in the male, these are formed from A9 cells (reviewed in Sánchez and Guerrero, 2001; Estrada et al., 2003). In comparison to'the genitalia primordia in each sex, the male A8 and the female and A9 primordia grow less and develop smaller structure/s, namely the tergite eight (T8) and the paraovarias (Keisman et al., 2001). The A10 segment in both sexes gives rise to the analia and the hindgut; however, the analias are dimorphic (reviewed in Sánchez and Guerrero, 2001; Estrada et al., 2003). In contrast to other imaginal cells, part of the domain of cells expressing engrailed (en) is not established during the embryonic stage (Casares et al., 1997; Chen et al., 2005). Finally, during male development, the A8 cells direct a dextral $360^{\circ}$ rotation (Gleichauf, 1936, Spéder et al., 2006).

Apoptosis, which occurs during Drosophila development, participates in the regulation of growth (reviewed in McCarthy, 2003). Nevertheless, its contribution and the events that trigger death during normal growth are poorly understood. It has been shown that apoptosis controls growth and it is triggered in the wing disc, when a mechanism of cell competition is in operation (Morata and Ripoll, 1975; Moreno et al., 2002a; de la Cova et. al., 2004;

Abbreviations used in this paper: en, engrailed; JNK, Jun- $\mathrm{NH}_{2}$-terminal kinase; $\mathrm{NE}$, no effect; O, overgrowth; RT, rotated terminalia.

\footnotetext{
*Address correspondence to: Ana Macías. Laboratorio “Genética del Desarrollo" FCEFN-UNC, Av. Vélez Sarsfield 299, 5000 Córdoba, Argentina. Fax: +54-351-433-2097. e-mail: amacias@com.uncor.edu
} 
Moreno and Basler, 2004). Thus, if adjacent cells are genetically modified to differ in their growth conditions i.e rate of proliferation (Moreno and Basler, 2004), those with the less proliferative genotype are removed by apoptosis. It is unknown whether cell competition occurs normally. It is known that up to $50 \%$ apoptotic cells induction in the wing disc, does not change the adult wing size, suggesting that apoptosis is compensated for by increased proliferation in the vicinity. A compensatory mechanism would involve prevention of death in targeted cells, their abnormal growth and secretion of growth factors, thus leading to the proliferation of surrounding tissues, which eventually leads to overgrowth (Ryoo et al., 2004; Pérez-Garijo et al., 2004; Huh et al., 2004; Pérez-Garijo et al., 2005). Therefore, the execution of death does not change growth, while the prevention of it does. Apoptosis in Drosophila involves the fine-tuned regulation of certain factors and pathways, including the activation of the Jun$\mathrm{NH}_{2}$-Terminal Kinase pathway (JNK), the degradation of Drosophila Inhibitor of Apoptosis 1 (DIAP1) (Yoo et al., 2002) by proapoptotic products (Grether et al., 1995; White et al., 1996; Chen et al., 1996) and the activation of caspase enzymes (reviewed in Abrams, 1999). Remarkably, McEwen and Peifer (2005) recently showed that in the absence of JNK activation direct death can take place, thus revealing a JNK-independent apoptotic pathway.

The JNK pathway is an intermediate in the apoptotic cascade; it behaves as a strong and weak regulator of the pro-apoptotic genes head involution defective (hid) and reaper (rpr) respectively in the eye antenna disc (Moreno et al., 2002b), while it is an rpractivator in the wing disc (McEwen and Peifer, 2005). JNK is also associated with the induction of the secretion of growth factors which compensate death (Ryoo et al., 2004), and has other activities which are independent of death (reviewed in Xia and Karin, 2004). In the male genital disc, apoptosis is likely to play a role in terminalia rotation, since rotated male terminalia have been found as a result of hidmutations, of hemizygosity for the death-promoting genes rpr, hidand grim (in DfH99/+ flies), of alterations in the JNK pathway, of death prevention by the P35 baculovirus protein and of mutations in genes encoding the caspases dronc, drice and Dcp1 (Abbott and Lengyel, 1991; Macías et al., 2004; McEwen and Peifer, 2005; Krieser et al., 2007; Muro et al., 2006). The JNK pathway is also known to participate in female genital disc development (Polaski et al., 2006). However, the precise roles of apoptosis and the JNK pathway in genital disc growth during development have not yet been studied in these imaginal cells.

To analyze in detail the effects of apoptosis and activation of the JNK pathway on genital disc growth, we have examined the tissue domains where JNK is activated and the patterns of expression of different genes associated with the apoptotic pathway. To study the role played by JNK and apoptosis in normal growth of the genital disc, we inhibited these processes by targeting the expression of the JNK negative regulator, Puc (Martín Blanco et al., 1998), and anti-apoptotic factors, DIAP1 (Hay, 2000) and P35 (Hay et al., 1994,) in the genital disc using the Gal4/UAS method (Brand and Perrimon, 1993). P35 was expressed singly in one or two doses, as well as in combination with Puc. Two drivers, which are expressed in organ primordia in both sexes, were used.

Our results show that the JNK pathway is subject to temporal, spatial and genitalia-specific regulation. Males express Hid and are sensitive to lower Hid levels, as well as to the dose of apoptotic genes, indicating that males, not females, require Hid function. In contrast, rpris expressed similarly in both sexes. The levels of rpr are particularly high at the antero-posterior (A/P) border cells. The pro-apoptotic factors Hid and rprappear subject to certain degree of inactivation. We show that JNK is an rpractivator in encells. en expressing cells are a target of the death pathway and part of the en domain is removed by apoptosis. JNK-mediated death in en cells is relevant in the growth of the analias. In the A8 primordia, JNK function appears to be important for the activation of rpr, since the levels of pro-apoptotic factors acts on proliferation. The regulation of pro and anti-apoptotic factors is especially important at the A/P borders to favor orderly growth. These results may contribute to improving our understanding of the growth of complex structures, such as Drosophila genital discs, as well as certain tumors and malformations in other organisms.

\section{Results}

\section{The JNK pathway is active in genital discs}

To examine if the JNK pathway plays a role in growth control in the genital disc, we first analyzed JNK activation in both sexes, by means of monitoring expression of the reporter (puc-Gal4) UAS-GFP; Pastor-Pareja et al., 2004) which we refer to more simply as JNKREP. First, we tested if this reporter responds to JNK activation. Exogenous expression of Puc led to reduced GFP expression (Fig. 1 A-B and $E$ compared with $C$ and $G$ ). In contrast, upregulation of JNK activation with constitutive activation in all cells can be achieved by Hep ${ }^{\mathrm{CA}}$ expression (constitutively active Hemipterus, Drosophila JNKK) using the puc-Gal4 driver; embryonic lethality ensues. However, the temporal expression of HepCA for a short period at L3 by tubulin-Gal80 ${ }^{\text {TS }}$ (McGuire et al., 2003) resulted in JNKREP expression in the genital disc which was limited to only a few cells, which were also positive for the apoptotic marker active caspase 3 (CAP3) (Fig. 1 A-B and E compared with F-F'). These findings suggest that the other JNKREP expressing cells had already died during this period. In these discs, many CAP3 positive nuclei were JNK ${ }^{\text {REP }}$ negative, suggesting that not all death involves JNK activation (Fig. 1 F-F'). It is remarkable that another reporter for JNK activity, the puc ${ }^{\mathrm{ES}}$ lacZ transgene (Martín-Blanco et al., 1998), showed the same L3 expression as the reporter we used, confirming the insertion of Gal4 in puc (Fig. 1 A,B,E compared with D,H).

Expression of JNK ${ }^{R E P}$ during the larval and pupal stages was found to be very dynamic, asymmetrical and genitalia specific. The levels of JNKREP are higher and more widespread in females than in males, indicating that in females, there is a less repressive environment for JNK activation. In both sexes in all stages analyzed, JNK ${ }^{\mathrm{REP}}$ was found to be expressed in some anterior A8 cells and in a subset of en A10 cells (Fig. 1 A-B and E, arrows); these probably correspond to stalks cells (Keisman et al., 2001). In males, JNKREP at late L3, apart from the stalks cells, can be seen in cells at the A8 A/P border (Fig. 1 A-B, arrowheads). In females at the same stage, JNKREP appeared in the stalks (Fig. $1 \mathrm{E}$, arrows) and in scattered enand anterior cells all over the disc. However, its expression was more concentrated around the A8 A/ $P$ border (Fig. 1E, arrowhead). A different pattern was detected at the pre-pupa stage (Fig. 1 I-I" and J-J"). Here, the expression of $J K^{R E P}$ was found to be particularly sexually dimorphic in the 
JNKREP

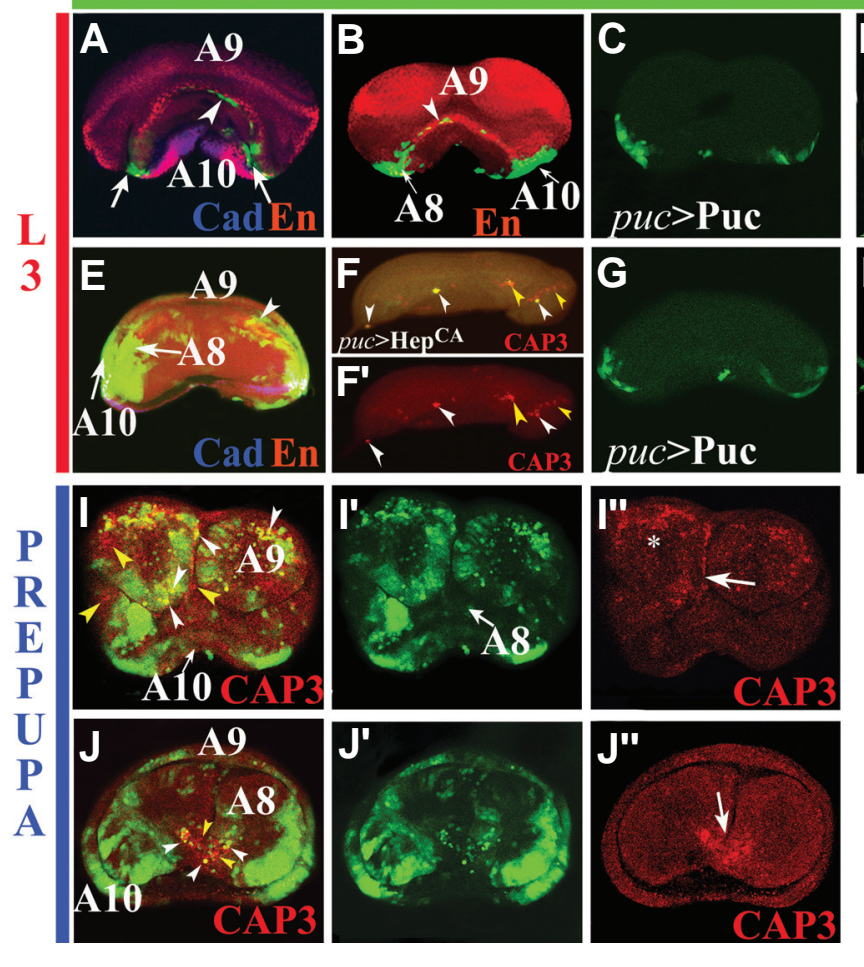

genitalia primordia. In the male A9 genitalia primordium, we observed random expression together with a continuous band bordering the left and right halves of the bilateral region (Fig. $1 \mathrm{I}$ I'). In the female A8 genitalia primordium, JNK ${ }^{R E P}$ expression was confined to the lateral left-right regions and to scattered cells at the bilateral region (Fig. $1 \mathrm{~J}$-J').

Finally, JNKREP was found to be co-expressed with CAP3 (Fig. $1 \mathrm{I}-\mathrm{I}$ " and J-J", white arrowheads in I-J), suggesting that JNK is active in apoptotic episodes and might be mediating death. Nevertheless, we once again detected a number of CAP3 positive cells which did not express JNK ${ }^{\text {REP }}$ (Fig. 1 I-J, yellow arrowheads), so not all death appears to require JNK activation. The apoptotic episodes shown are those detected between the left and right halves of the genitalia primordia, thus indicating that apoptosis occurs in these regions (Fig. 1l'- J", arrows). In addition, in the male, apoptosis is abundant in the region that includes the mesodermal cells (Ahmad and Baker, 2002) (Fig. 1l', asterisk).

\section{Expression and function of pro-apoptotic genes in the geni- tal disc}

The pattern of Hid expression in the male disc at $L 3$ is shown in Fig. 2A. We detected Hid in A8, A9 and A10, which agrees with the hid hypomorph phenotype in these segments (Fig. 2C). Interestingly, in the female genital disc, we did not detect a Hid signal at L3 (data not shown). Due to sex differences, we analyzed the female external terminalia of the hid hypomorph ( hid A22) DfH99). We did not observe any major differences between hid hypomorphs and wild-type individuals, indicating that female development does not depend on hid. We also observed that, in contrast to males, hemizygosity for the death-promoting genes rpr, hid and grim (DfH99/+) did not result in any obvious pheno-

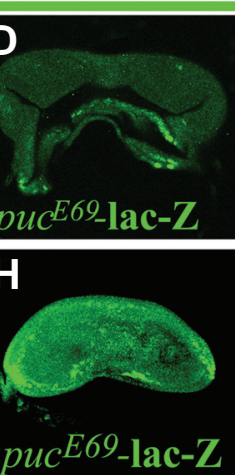

Fig. 1. JNK activation at L3 and in pre-pupa discs. Green fluorescence (GFP) is indicative of the JNK REP signal. Notice that JNKREP expression is asymmetric in all the discs. (A-D) Males. (A,B) JNKREP in the stalks (arrows) and in the A8 A/P border cells (arrowheads). (C) Exogenous expression of Puc directed by its own promoter (puc $>$ PUC) reduces JNKREP expression (compare with $A, B)$. (D) JNK activation shown by the reporterpuc ${ }^{\mathrm{E69}}$ - lac$Z$ does not differ from that of JNKREP (compare with $A, B$ ). (E-H) Females. (E) JNK REP in the stalks (arrows) and in scattered cells at the A8 A/P border (arrowhead). (F, $\left.\mathbf{F}^{\prime}\right)$ Upregulation of JNK reduces the number of cells which coexpress JNKREP and caspase3 (CAP3) (white arrowheads), while many CAP3+ cells are JNK ${ }^{R E P}$ - (yellow arrowheads). (G) The JNK ${ }^{R E P}$ signal is reduced due to ectopic Puc expression (compare with E). (H) JNK activation shown by the reporter puc E69- lac-Z does not qualitatively differ from that of JNKREP in females. However, the sensitivity of detection is superior in JNK ${ }^{R E P}$ (compare with E). (I-I', J-J') Prepupa discs. (I-I') Male. JNKREP in A9 borders the area of contact between the halves; outside this area it is random. Huge CAP3+ spots are JNK ${ }^{R E P}+$ (white arrowheads, I), while others are JNK ${ }^{R E P}$ - (yellow arrowheads, I). Notice the fine CAP3+ granules present in all the cells (I'). (J-J') Female. In A8, JNKREP is at the left and right lateral sides and in scattered cells in the bilateral and anterior regions. Some CAP3+ are JNKREP + (white arrowheads, J), whereas others are JNK ${ }^{R E P}$ - (yellow arrowheads, J). Notice the fine CAP3+ granules present in all the cells ( $\left.\mathbf{J}^{\prime \prime}\right)$. types in females, indicating that female genital development proceeds normally in the presence of lower levels of these apoptotic factors.

The expression domain of the pro-apoptotic gene rprat L3 was determined by the reporter fusion construct rpr-lac $Z$ (Nordstrom et al., 1996), which we call Rpr REP. Rpr REP was seen in all of the genital disc cells in both sexes, but is expressed at higher levels in females. Rpr REP expression is upregulated at the A/P borders and in the stalks (Fig. 3 A-A" and C-C"). As JNK is an rpractivator in others contexts (Moreno et al., 2002b; McEwen and Peifer, 2005), we examined if it acts similarly in the genital disc. Direction of expression of Puc, a JNK negative regulator, in the endomain strongly reduced $\mathrm{Rpr}^{\mathrm{REP}}$ expression, indicating that the JNK pathway is an rpr activator (Fig. 3 B-B"'and D-D'). We also observed an increased density of nuclei in the endomain under conditions of JNK inhibition, suggesting some JNK-mediated death might be prevented and that increased proliferation may be due to a compensatory mechanism associated with the death
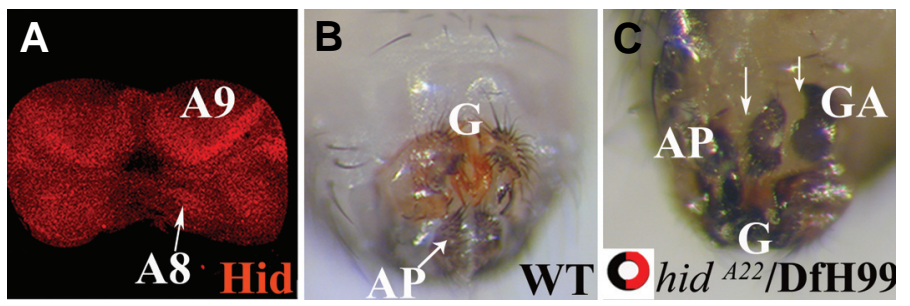

Fig. 2. Male Hid expression and phenotype. (A) Wild-type (WT) L3 disC. (B) Wt male terminalia. (C) hid ${ }^{\text {A22 } / D f H 99 ~ m a l e ~ w i t h ~ r o t a t e d ~ t e r m i n a l i a ~ a n d ~}$ overgrowth between the anal plates (AP) and genital arch (GA) (white arrows). In this and following figures, the degree of rotation is indicated by the red trajectory indicated at the bottom left corner. 


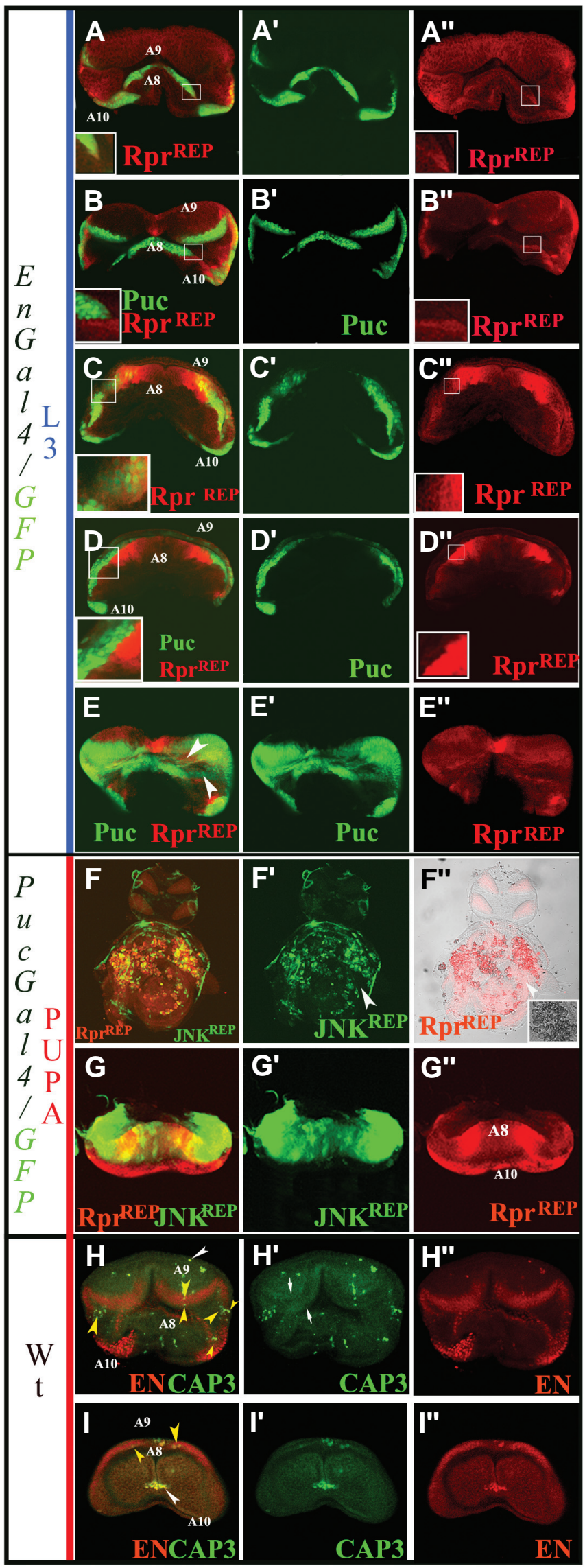

process (Ryoo et al., 2004; Huh et al., 2004; Pérez-Garijo et al., 2004; Pérez-Garijo et al., 2005) (Fig. 3 A-B and C-D, see the insets for comparison). Indeed, direction of Puc expression blocked apoptosis in encells in the male, since rows of these cells which are never seen at this stage, appeared (Fig. 3E-E", arrowheads E). Finally, JNK ${ }^{R E P}$ and Rpr ${ }^{R E P}$ exhibited partial co-expression in pupa genital discs (Fig. 3 F-F" and G-G"). In males, the coexpressing cells exhibited a different morphology from the rest of the cells, suggesting that they might be apoptotic (Fig. 3F") and that JNK is up-regulated in Rpr-death regions in males.

Apoptotic gene activity leads to the activation of caspases (Yoo et al., 2002). In a genital disc environment expressing hid and/or $r p r$, we analyzed active caspases in wild-type discs. In both sexes, caspase(s) activation, visualized by an antibody to active CAP3, was seen as fine bright positive spots in all cells (Fig. 3 H-H", I-I" and Fig. 1 l"-J"), as well as a few large spots which are nuclei of apoptotic cells. In males, active caspases are more abundant and are present at a higher density in the endomain (Fig. $3 \mathrm{H}^{\prime}$, arrows), which is consistent with the expression of Hid in this sex. However, the expression pattern of active caspases does not coincide with that of Hid and RprREP, pointing to mechanisms which inactivate these proteins (Kurada and White, 1998; Bergmann et al., 1998; Tsujimura et al., 2008). Finally, in these discs, few en nuclei at the A/P borders were CAP3 positive (Fig. $3 \mathrm{H}-\mathrm{I}$, yellow arrowheads), while some were found outside the borders (Fig. 3 $\mathrm{H}-\mathrm{I}$, white arrowheads). This indicates that encells are targets of death, there are few en death regions at the borders and part of the en domain is removed by apoptosis.

\section{JNK and apoptotic activity in genital disc development}

We have shown that there is JNK activity in the genital disc. To determine if there is any role for this pathway in apoptosis, we analyzed the effects of blocking JNK and the activation of caspases.

\section{The male A8 primordium}

The $A b d-B$-Gal4LDN line (de Navas et al., 2006) expresses in the genital disc, in the A8 primordium, with low levels in the en domain (Fig. 4A arrow), and also in cells outside of A8 (Fig. 4A, asterisk). In the adult, expression was detected in T8 (Fig. 4G, arrow), in cells of the external and internal genitalia (Fig. 4G, asterisk, and data not shown) and in the hindgut (data not shown). Expression outside A8 likely belongs to cells of A8 mesodermal origin, as they are only present in the male (Ahmad and Baker,

Fig. 3. Expression of the pro-apoptotic gene rpr and active caspases. (A-B', E-E') Males. (C- $\left.\mathbf{D}^{\prime \prime}\right)$ Females. (A-A"' and C-C') Rpr ${ }^{R E P}$ is upregulated in the A/P borders cells. (B-B", D-D" and E-E") Notice the sharp reduction of $R p r^{R E P}$ expression in en cells due to the directed expression of Puc in these cells. Also note the increase in en GFPexpressing cells (Compare insets $A, B ; A^{\prime \prime}, B^{\prime \prime} ; C, D$ and $\left.C^{\prime \prime}, D^{\prime \prime}\right)$. (E-E") Observe the new appearance of en cells which are never seen at this stage (arrowheads). (F-F") Male pupa. JNKREP is co-expressed with $R p r^{R E P}$ in seemingly apoptotic cells (inset in $F^{\prime \prime}$ ), while they are not in cells with a non-apoptotic appearance (arrowheads $\left.F^{\prime}-F^{\prime \prime}\right)$. (G-G') Female prepupa disc. JNK ${ }^{R E P}$ expression partially overlaps with that of $R p r^{R E P}$. $(\mathbf{H}-$ $\left.\mathbf{H}^{\prime \prime}\right)$ Male and (I-I") female wild type (WT) pre-pupa discs. Fine CAP3+ spots are seen in all cells in both sexes, with there being more in the male (compare $H^{\prime}$ with $I^{\prime}$ ), especially in en cells (arrows in $H^{\prime}$ ). Some en nuclei are CAP3+ at the A/P borders (yellow arrowheads) and outside them (white arrowheads). 
2002). We did not analyze these cells, but, in contrast to cells in the primordium, they proliferate at L3 in response to caspase inhibition, indicating that these cells are targets of death. Consequently, these cells behave differently in larva than in the primordium (shown below).

The male A8 primordium exhibits a low rate of growth (Sánchez and Guerrero, 2001). Indeed, we could only detect a few dividing cells, as determined by the cell division marker anti-phosphohistone 3 (PH3) (Su et al., 1998), whereas many were found in A9 (Fig. 4B). The A8 cells direct a clockwise $360^{\circ}$ rotation (Spéder et al., 2006) and this process might require apoptosis (Macías et al., 2004). We reasoned that if cell death is instrumental in the male A8, suppression of apoptosis should result in a larger A8. However, inhibiting apoptosis by expressing DIAP1 (Hay, 2000) or P35 (Hay et al., 1994) did not affect A8 growth, but it did cause incomplete rotation (Fig. $4 \mathrm{H}$, arrow, Table 1 and data not shown). These results indicate that DIAP1 and P35 at these levels are unable to prevent death, but do interfere with rotation.

In the light of the above results, and of other data (Jiang et al., 1997) showing that one dose of P35 can not completely prevent apoptosis, we decided to analyze the effects of a double dose of P35. In $A b d-B-B^{L D N / 2 x P 35 / G F P ~ a d u l t s, ~ t h e ~ m a l e ~ t e r m i n a l i a ~ w e r e ~}$ found to be incompletely rotated (Fig. 4I), and a notable overgrowth was produced in the ventral abdomen, which split the genital arch (GA) and the anal plates (AP). This showed that we had prevented apoptosis in the primordium and regions outside the primordium (GA-AP growth). The GFP-positive cells within the GA and AP exhibited low fluorescence, which is consistent with the low expression of the driver in en cells. The inhibition of death in the enregion outside A8 can be explained by the previous proposal that the en domain originates from one primordium of cells (Chen et al., 2005). Alternatively, Martín et al. (in press) reported that en cells acquire migratory properties when their death is prevented (undead cells).

When we looked at the primordium of $A b d-B-B^{L D N} / 2 \times \mathrm{P} 35 / \mathrm{GFP}$ discs, we observed that its size had not changed. Moreover, its

Fig. 4. Effects of modifying the JNK pathway and caspase activity on male $\mathbf{A} 8$ primordium growth. Abd-B-Gal4 ${ }^{L D N}$ expression is shown by one dose of UAS-GFP with the exception of (A). A8 GFP+ cells outside of $A 8$ are indicated by asterisks. (A-F) Discs. (G-K') Adults. (A) The Abd$\mathrm{B}-\mathrm{Ga} / 4^{L D N}$ driver is expressed in anterior and posterior A8 cells, but at a low level in the posterior cells (arrow). (B) In the A8 primordium, fewer cells are dividing with respect to A9. (C) The direction of 2xP35 expression does not alter $A 8$ primordium growth at $L 3$, but it does alter growth outside the $A 8$ (compare with $A, B$ ). (D,E) Growth of the $A 8$ male primordium is increased in larvae due to changing the levels of the apoptotic gene products in different ways (compare with $A, B$ ). (F) A8 primordium growth notably changed by directing Puc expression together with P35. (G) Driver expression in the adult corresponds to T8 (arrow) and to A9 derivatives (asterisk). (H) Overexpression of DIAP1 prevents rotation and does not alter A8 growth (arrow). (I) Adults with 2xP35 expression show a notable A8 ventral abdominal overgrowth (arrowheads) which continues to split the GA and AP (arrow). (J) The direction of Puc expression does not produce overgrowth in adults (arrow). (K, $\left.\mathbf{K}^{\prime}\right)$ The adult phenotype of Puc; P35 directed expression is similar to that produced by $2 \times P 35$ (I). In these adults, there is an abdominal ventral dark band, which is a sign of necrosis (white arrowhead, $K^{\prime}$ ), and there also appears to be hairs (black arrowheads) which never develop in the sixth sternite. These features are both indicative of the prevention of apoptosis. mitotic behavior was unaltered (Fig. 4C vs.B). Therefore, apoptosis in the primordium does not take place in larvae, but it does outside of $A 8$ since $A b d-B-B^{L D N / 2 x P 35}$ notably increased growth there (Fig. $4 \mathrm{C}$ vs. B). To confirm that apoptosis in the primordium takes place in pupae, we expressed 2xP35 at different times of development using the Gal80 $\mathrm{TS} / \mathrm{Gal} 4$ system (McGuire et al., 2003). Blocking transcription of 2xP35 in larval stages (permitting apoptosis) and allowing it in pupae (preventing apoptosis), resulted in $92 \%$ of males with rotated terminalia, whereas $73 \%$ of them had, in addition, a severe overgrowth phenotype, similar to control animals grown at $30^{\circ} \mathrm{C}$ throughout development. In contrast, when 2xP35 protein was expressed in larvae (preventing

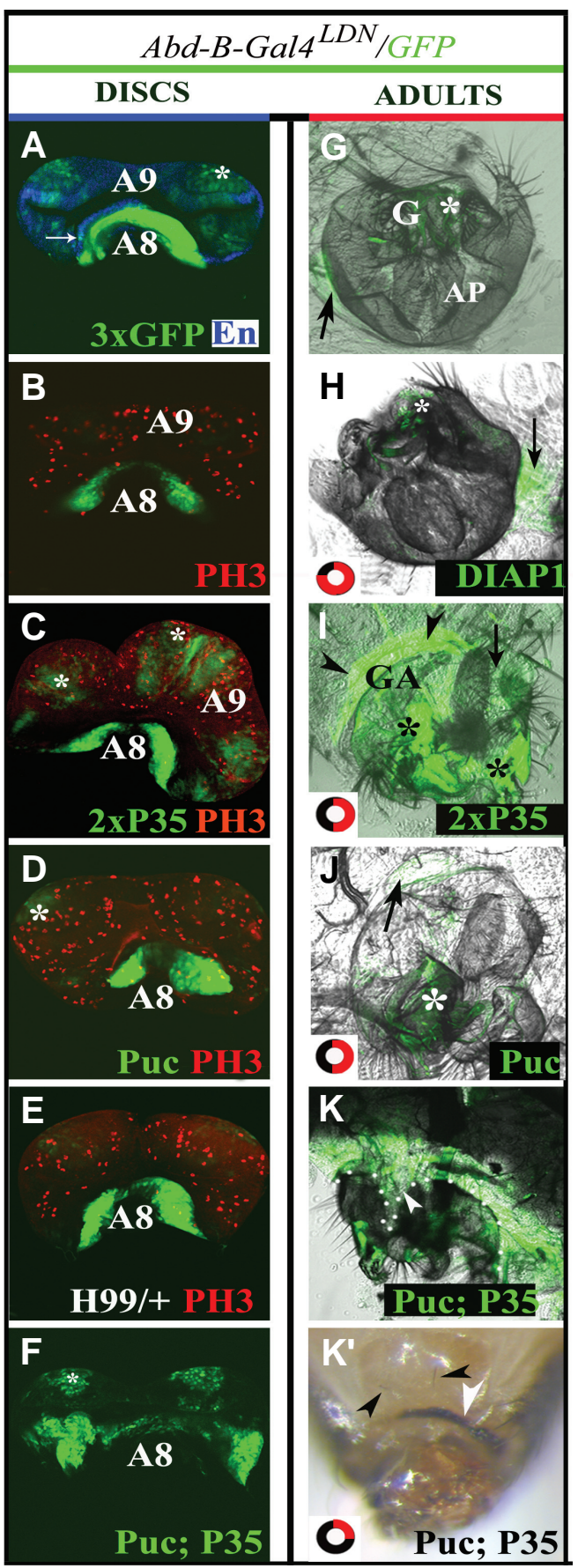


apoptosis) and blocked in pupae by Gal80 (allowing apoptosis), only $52 \%$ of adults had rotated terminalia, without visible effects on overgrowth. These results confirm the idea that apoptosis occurs normally at the pupa stage. The pupal death window, having detected Hid and RprREP expression in larvae (Fig. 2A and Fig. 3 A-A"), indicated that there are mechanisms which partially inactivate the pro- apoptotic factors. These mechanisms in addition with the anti apoptotic activity of DIAP1 would determine a cellular equilibrium at larva that delay the ocurrence of death.

We tested the role of JNK in mediating death. The expression of Puc did not change adult A8 growth alone or when simultaneously co-expressed with a JNK dominate negative form (Bsk ${ }^{\mathrm{DN}}$ ) (Fig. 4J and Table 1) suggesting that JNK may be irrelevant in mediating death. Curiously, examination of L3 discs revealed that, in contrast to 2xP35, direction of Puc expression increased growth of the A8 in larvae, indicating that some JNK-mediated death had been prevented (Fig. 4D vs. B and C). This change was more apparent in cells that were $\mathrm{PH} 3$ positive and GFP positive. In addition, growth was asymmetric, which is in accordance with the asymmetric expression of JNKREP (Fig. 1 A-B). Even though the change in growth might be due to JNK activity, rather than to apoptotic genes, we found that the same phenotype is produced by the lower apoptotic gene dose (Fig. 4E vs. D-B).

Since DfH99/+ adults exhibit rotated terminalia, this result indicated, first, that some death is prevented by this way and second, that certain levels of the apoptotic factors are necessary to execute this death.

Having changed growth at the larva stage, we next asked if more death might be taking place due to the compensatory mechanism (Huh, et al., 2004; Ryoo et al., 2004) which should produce local changes in proliferation. To address this question, we simultaneously expressed Puc and P35, which should block direct apoptosis (McEwen and Peifer, 2005). This notably changed A8 growth in larvae, more so than when Puc alone was expressed (Fig. 4F vs. D), indicating that direct death had been prevented. Accordingly, the adult phenotype of $A b d-B-B^{L D N} / \mathrm{Puc}$; P35/GFP was similar to that of $A b d-B-B^{L D N} / 2 \times \mathrm{P} 35 / \mathrm{GFP}$ (Fig. $4 \mathrm{~K}-\mathrm{K}^{\prime}$ vs. I). However, individuals of the former genotype always had a dark band across the ventral abdomen, which was probably necrotic tissue (Fig. 4K'), indicating that apoptosis was effectively blocked and that the target cells die by an alternative pathway (Chang and
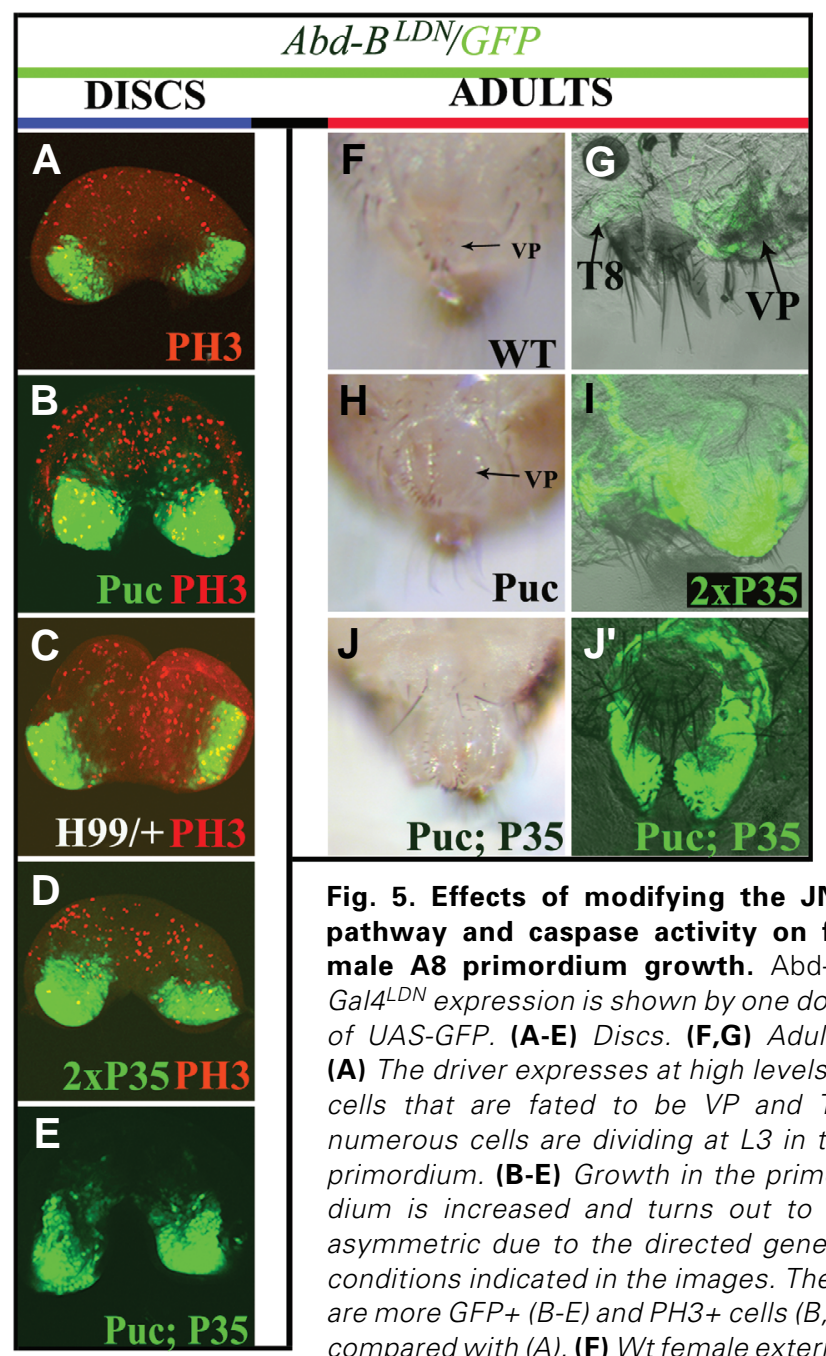

Fig. 5. Effects of modifying the JNK pathway and caspase activity on female A8 primordium growth. Abd-BGal4 ${ }^{L D N}$ expression is shown by one dose of UAS-GFP. (A-E) Discs. (F,G) Adults. (A) The driver expresses at high levels in cells that are fated to be VP and T8; numerous cells are dividing at $L 3$ in the primordium. (B-E) Growth in the primordium is increased and turns out to be asymmetric due to the directed genetic conditions indicated in the images. There are more GFP+ $(B-E)$ and $P H 3+$ cells $(B, D)$ compared with (A). (F) Wt female external genitalia. (G) Driver expression in adults corresponds to VP and T8 (arrows). (H) The direction of Puc expression produces, in the adults, a slightly unequally larger VP (arrow, compare with F). (I) Adults with 2xP35 expression show notable overgrowth of VP and T8; compare with $G) .\left(\mathbf{J}, \mathbf{J}^{\prime}\right)$ Reminiscent of $2 x P 35$, the directed expression of Puc with P35 produces hyperplasic growth of VP and T8.

TABLE 1

\section{SUMMARY OF DISC AND ADULT GROWTH PHENOTYPES WHEN ACTIVITIES OF THE JNK PATHWAY AND CASPASES ARE MODIFIED}

\begin{tabular}{|c|c|c|c|c|c|c|c|c|c|c|}
\hline Gal4 & UAS & & GFP & DIAP1 & P35 & $2 \times P 35$ & $\mathrm{BSK}^{\mathrm{UN}}$ & PUC & $\mathrm{BSK}^{\mathrm{UN}} ; \mathrm{PUC}$ & PUC; P35 \\
\hline \multirow{4}{*}{$\begin{array}{l}\text { Abd- } \\
B^{\mathrm{LDN}}\end{array}$} & \multirow[b]{2}{*}{ MALE } & Disc & A8 & -------- & ---------- & $\mathrm{NE}$ & --------- & $\mathrm{O}^{*}$ & -------- & $\mathrm{O}^{* * *}$ \\
\hline & & Adult & $\mathrm{T} 8$ & $42 \% \mathrm{RT}$ & $100 \% \mathrm{RT}$ & $\begin{array}{l}30 \% \text { RT } \\
70 \% \text { RT\&O*** }\end{array}$ & $100 \% \mathrm{RT}$ & $100 \% \mathrm{RT}$ & $100 \% \mathrm{RT}$ & $100 \% \mathrm{RT}^{2} \mathrm{O}^{\star \star \star}$ \\
\hline & \multirow[b]{2}{*}{ FEMALE } & Disc & A8 & ------- & --------- & $\mathrm{O}^{\star \star \star}$ & 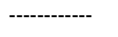 & $\mathrm{O}^{*}$ & --------- & ---1---- \\
\hline & & Adult & T8-VP & $7 \% \mathrm{O}^{*}$ & $100 \% \mathrm{O}^{*}$ & $100 \% \mathrm{O}^{\star \star \star *}$ & $15 \% \mathrm{O}$ * & $20 \%$ * & $20 \% \mathrm{O}^{*}$ & $100 \% \mathrm{O}^{* * *}$ \\
\hline \multirow{4}{*}{ cad } & \multirow[b]{2}{*}{ MALE } & Disc & A10 & ------- & ----------- & --------- & ---------- & ---------- & ---------- & ------------ \\
\hline & & Adult & AP-PR & $73 \% \mathrm{RT}$ & $\begin{array}{l}\text { 12\%RT } \\
35 \% \text { RT\&O* }\end{array}$ & $\begin{array}{l}30 \% \text { RT } \\
70 \% \text { RT\&O*** }\end{array}$ & $9 \% \mathrm{RT}$ & $\begin{array}{l}30 \% \text { RT } \\
70 \% \text { RT\&O*** }\end{array}$ & ----------- & $100 \% R T \& O^{* * *}$ \\
\hline & \multirow[b]{2}{*}{ FEMALE } & Disc & A10 & -------- & ------- & --------- & -------- & ---------- & ---------- & ---------- \\
\hline & & Adult & AP-PR & $100 \% \mathrm{O}^{*}$ & $100 \% \mathrm{O}^{*}$ & $100 \% \mathrm{O}^{\star \star \star}$ & $100 \% \mathrm{O}^{*}$ & $100 \% \mathrm{O}^{\star \star \star}$ & --------- & $100 \% \mathrm{O}^{* * *}$ \\
\hline
\end{tabular}

\footnotetext{
* asterisk(s) represent degree of overgrowth
} 
Yang, 2000). In summary, A8 primordium growth proceeds without the occurrence of death in larvae, but death occurs when the levels of pro apoptotic factors change. In this sense, since JNK and rprare upregulated in A8 A/P border cells (Fig. $1 \mathrm{~A}-\mathrm{B}$ and $3 \mathrm{~A}-$ $A^{\prime \prime}$ ) and death seems to be directed towards en cells, JNK activation of rprappears to be one cause of the growth, rather than the death, of these cells in larvae.

\section{The female $A 8$ primordium}

$A b d-B$-Gal4 ${ }^{\mathrm{LDN}}$ showed expression in the disc in cells destined to be part of the vaginal plates (VP) and T8 (Fig. 5A), and it was more weakly expressed in the rest of the primordium (de Navas et al., 2006; data not shown). Accordingly, expression in adults was detected in VP and T8 (Fig. 5G). We analyzed A8 growth in the discs, but, in the adults, we only analyzed the external structures.

Female A8 cells develop in a sexual context which is different to that of homologous cells in the male (reviewed in Sánchez and Guerrero, 2001, Estrada et al., 2003). One difference, which can be observed at $L 3$, is that they exhibit a high rate of cell division (Fig. 5A vs. Fig. 4B). The direction of Bsk ${ }^{\mathrm{DN}}$ or Puc expression resulted in a weak phenotype of unequal larger VPs (Fig. $5 \mathrm{H}$ vs. F), which was not altered when both were expressed together (Table 1), pointing to a minor role for JNK-mediated death. Accordingly, the discs exhibited increased growth (more PH3-positive and GFP-positive cells), which was asymmetric (Fig. 5B). Interestingly, a similar phenotype in the discs only, was produced by the lower dose of apoptotic genes (Fig. 5C), indicating the levels of pro apoptotic factors are able to influence proliferation perse. Therefore, the regulation of these factors are not only necessary for the execution of death but also to determine the rate of proliferation.

In accordance with a minor role of JNK-mediated

Fig. 6. Effects of modifying the JNK pathway and caspase activity on analia growth. Cad and en driver expression is shown by UAS GFP and is indicated in the figure. (A,B) cad driver expression in the discs overlaps with en $A 10$ expression (white arrowheads). (C,D) The En A10 domain in adults corresponds to perianal ring (PR) cells (white arrowheads). It resides in between the anal plate in males (C) and the hemi-anal plates in females (D). (E) Wt male terminalia, dorsal view. Notice the morphology of the GA and T8. (E'-E') In male adults, driver expression corresponds to the AP (arrows) and the PR (arrowhead). (F) The analia of a wt female (arrow). (F') In female adults, driver expression corresponds to the $A P$ (arrow) and the $P R$ (arrowhead). (G-I') Males and (J-L') females. Analia growth was severely affected due to the death-preventing conditions indicated in the figure. (G-I") Overgrowth of PR cells (arrowheads) splits the GA and T8. It also reduces and makes analia growth asymmetric (H, I', I') (compare with $E$ and $\left.E^{\prime}, E^{\prime \prime}\right)$. (J-L') In females, the overgrowth also corresponds to PR cells (arrowheads), splits the hemi-dorsal and ventral $A P\left(\mathbf{K}-\mathbf{K}^{\prime}\right)$ and highly reduces analia development (L) (compare with $\left.F, F^{\prime}\right)$. The overgrowth continues outside the primordium ( $L^{\prime}$, white arrowhead). death, over-expression of the anti-apoptotic (Hay, 2000) and JNK-related death factor DIAP1 (Kuranaga et al., 2002) affected adult growth in a manner which was similar to that due to the direction of expression of Puc or Bsk ${ }^{\mathrm{DN}}$ (Table 1). However, over-expressing P35 in a dose-dependent manner led to increased asymmetric growth at L3 (Fig. 5D vs. A). These results with $\mathrm{P} 35$ are in contrast to those observed in the male A8 at L3 (Fig. 4C), showing that death occurs in female larvae and that the levels of pro-apoptotic factors varies among death target cells. As in the larva, the adult structures exhibited overgrowth (Fig. 5I vs. G). Prevention of death by direction of Puc expression did not substantially alter the size of the adult structures (Fig. 5H), but the expression of 2xP35 did (Fig. 5I), suggesting that death can be generated in increasing amounts and in a direct manner. In this regard, the simultaneous direction of expression of Puc and P35 caused asymmetric over-

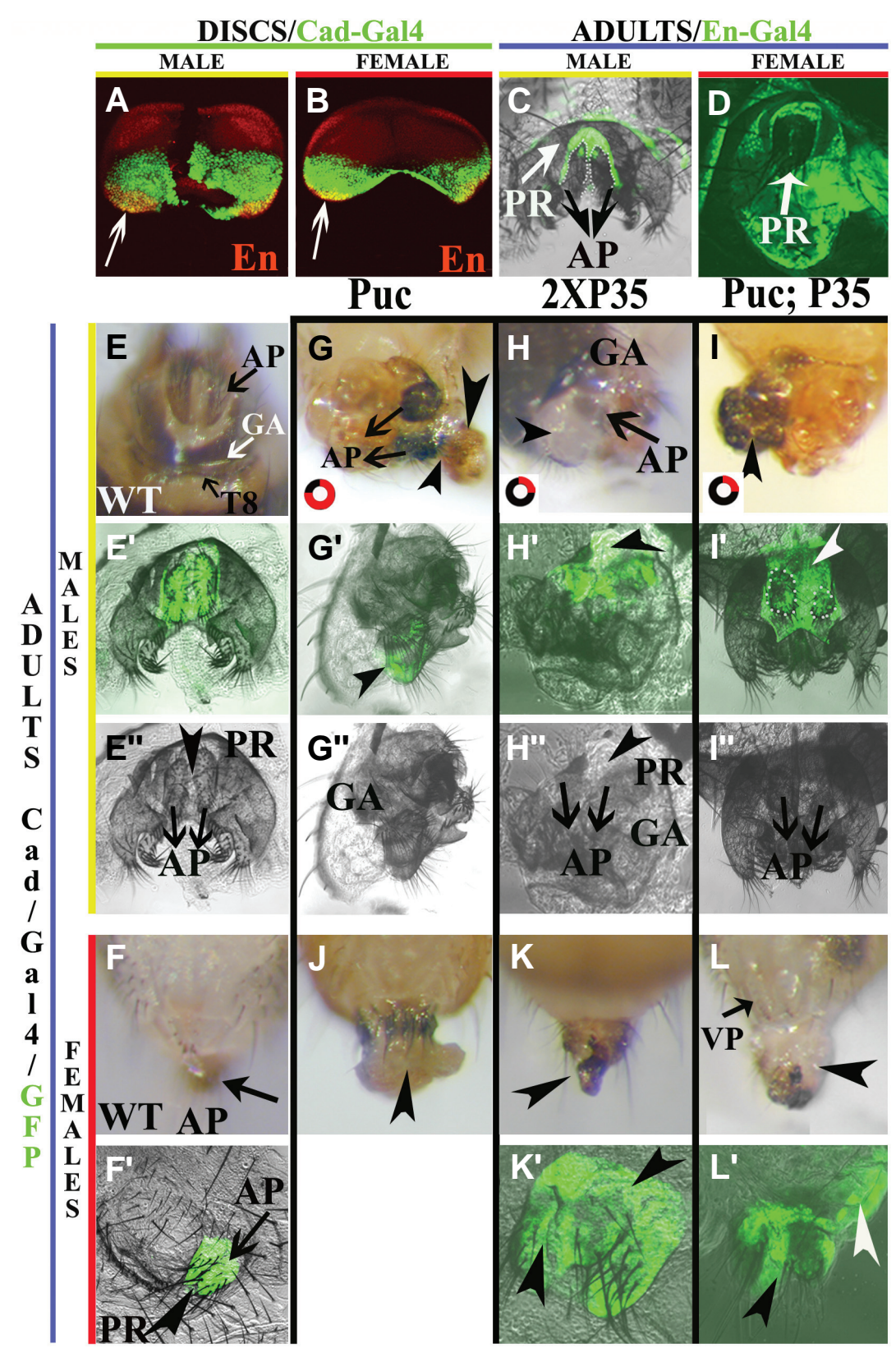


growth in the discs and in the adults (Fig. 5E and J-J'), reminiscent of the effects of 2xP35 alone (Fig. 5 D-I).

\section{Male and female analia growth}

The A10 primordia in both sexes give rise to the same structures, the analia and the hindgut, but analias are dimorphic. The only difference observed between male and female analia growth is the level of the apoptotic factors which induces apoptosis, so we considered treating them together. The driver used for A10 primordia was caudal-Gal4 (Calleja et al., 1996), referred to as cad. In the disc, it is expressed in the A10 primordium and overlaps with enexpressing cells (Fig. 6 A-B), which are destined to become the perianal ring (PR) (Fig. 6 C$D)$. In adults, it is expressed in both sexes in the anal plates (AP), in the PR (Fig. 6 E'-E'" and F') and in the hindgut (not shown).

In males, lowering JNK activity by directing the expression of $\mathrm{Bsk}^{\mathrm{DN}}$ in $\mathrm{A} 10$ cells prevented rotation (Table 1). However, overgrowth in the region of the PR, which expresses en, was observed when we directed Puc expression (Fig. 6 G-G"'vs. EE'), indicating that we had prevented death in en-cells by blocking the JNK pathway. The overgrowth split the GA and T8 (Fig. 6 G-G'), so death was also prevented outside the $A 10$ and should only affect en cells (Chen et al., 2005). Ectopic expression of P35 or DIAP1 resulted in adult males with rotated terminalia and overgrowth as well (Table 1). The overgrowth was augmented by increasing the dose of P35 or by expressing Puc with P35 (Fig. $6 \mathrm{H}-\mathrm{H}$ ' and I-I'), indicating that death of en cells can be induced by different levels of the apoptotic factors and even in the absence of JNK activation. Remarkably, abnormal growth prevails over normal growth, suggesting that cells targeted to die but prevented from doing so may obtain a growth advantage by means of the compensatory mechanism which is associated with the apoptosis process (Huh et al., 2004; Ryoo et al., 2004) (Fig. $6 \mathrm{H}$ and I').

In the female A10 primordium, inhibiting the JNK pathway by expressing Bsk ${ }^{\mathrm{DN}}$ or Puc, or by over-expressing P35 or DIAP1, prevented apoptosis, leading to overgrowth in A10 (Fig. 6J, arrowhead, Table 1 and data not shown). However, it was only necessary to lower JNK activation to produce overgrowth, so apoptosis in females proceeded with lower levels of apoptotic factors. The overgrowth in females, as in males, was augmented by increasing the dosage of P35 (Fig. 6K-K') or by coexpressing Puc with P35 (Fig. 6 L-L'), and this overgrowth included cells of other primordia (Fig. 6L', white arrowhead), which might be en cells (Chen et al., 2005) or are en A10 undead migratory cells (Martín et al., in press).

\section{Discussion}

\section{JNK, active caspase and apoptotic gene expression in genital disc development}

We have shown that, during genital disc development, the JNK pathway is activated and key elements of the apoptotic pathway are expressed. In particular, we have shown that a JNK reporter exhibits an asymmetric, dynamic and genitaliaspecific expression pattern. Expression of this reporter should reflect the sites where the positive inputs over the pathway overcome the negative ones. We have shown that JNK is an rpr activator. Therefore, JNK might be active and upregulated in all $\mathrm{Rpr}^{\mathrm{REP}}$ cells. However, the patterns of JNK ${ }^{\mathrm{REP}}$ and Rpr REP expression do not fully coincide. This could be due to the dynamic nature of JNK regulation and the cumulative nature of rprexpression. However, rprmight also be activated independently of JNK. Nevertheless, in males and in pupae, JNKREP and $\mathrm{Rpr}^{\mathrm{REP}}$ expression are coincidental in cells that appear to be apoptotic, suggesting that rpr could be activating JNK (Kuranaga et al., 2002). It is possible that such a positive feedback regulation may be necessary for the execution of JNKRpr-mediated death in males.

In keeping with the idea that the JNK pathway is an intermediate in the apoptotic pathway, we have shown that JNK is coexpressed with active CAP3 in both sexes. We did not show a relationship between hidand JNK, although some data suggest that JNK regulates hid (Moreno et al., 2002b) and vice versa (Ryoo et al., 2004). Nevertheless, we showed that male development, in contrast to female development, depends on the expression of Hid, suggesting that the male sex-determining gene is activating hidand implies a JNK-independent activation mechanism for this gene. This may explain the apoptotic nuclei observed in this sex which are JNKREP negative. In agreement with Hid and/or Rpr REP expression in the genital disc, we found active caspases in all cells. However, the patterns and levels of expression of the apoptotic factors or the reporter do not coincide with those of active caspases, indicating that the apoptotic factors are subject to inactivation.

\section{JNK and apoptotic genes function in overgrowth}

The JNK pathway, as a regulator of apoptotic genes, executes different functions depending on its level of activation, thus underlying the importance of JNK regulation. In the present study, we have been able to distinguish the growth functions of JNK in both sexes. The function of other elements of the apoptotic pathway, such as hid, rpror caspases, also seems to depend largely on their levels of activity.

Before analyzing the functions of JNK in overgrowth, it is necessary to elucidate the requirement for death and its detection among encells. Apoptosis occurs in genital discs development since the discs and the corresponding adult structures exhibit overgrowth in a P35 dose-dependent manner. We showed the requirement for JNK activation in some death by directing the expression of the JNK negative regulator Puc. However, death continues to occur in the presence of directed Puc expression and was demonstrated by the addition of P35 expression. It is expected that an independent promoter induces enough Puc expression to block JNK activation. Moreover, it should since the simultaneous co-directed expression of a JNK dominant negative form did not change the growth phenotypes due to Puc alone. Consequently, there is a JNK independent way to activate apoptotic genes and this could be in part through the activity of the sex-determining genes. In males, this gene could be hid. In females, we do not know if any of the other pro-apoptotic genes not analyzed here are subject to sex-specific regulation. Apoptosis among encells was demonstrated in different ways. En is co-expressed with active CAP3 in wild-type discs. Death in the A10 primordia occurs among en cells and finally, by the unexpected appearance in males of en cells at L3, when JNK is inhibited in this domain. 
We have found that the JNK pathway regulates growth control by means of regulating apoptotic genes in two ways. Firstly, by providing the expression levels necessary to execute some death and secondly, by activating rpr. The role of JNK in apoptosis and in en cells is evident in the A10 primordia. In contrast, in the A8 primordia, JNK does not play a relevant role in the death processes, but rather functions principally to activate rpr.

The second function of JNK is apparent in the male A8 primordium where growth proceeds without the occurrence of death in larvae. In this regard, it is important to note that Keisman et al.,2001) showed that the sex genes control the growth of genitalia primordia at the A/P borders from the patchedcells in a non-autonomous way. This implies that the $A /$ $\mathrm{P}$ borders, and even anterior and posterior cells, differ between the sexes in their growth conditions. One sex difference could be the activation of hid by the male sex gene, and its repression by the female counterpart gene. We found that death does not occur in male larval A8 due to the levels of pro apoptotic factors. Since death is required for the competition mechanism (Moreno et al., 2002a; de la Cova et. al., 2004, Moreno and Basler, 2004), this growth control mechanism must not be operative in this primordium at this stage. Consequently, JNK- rpr regulation at the A/P border, the probable activation of hidby the male sex gene and the activities that counteract apoptosis, DIAP1 and the inactivation of apoptotic products, determine scarce proliferation and non-death at the larval stage at the A/P border. Having shown that JNK ${ }^{\text {REP }}$ exhibits genitalia-specific regulation and that JNK activates rprin encells, one may ask if apoptotic factors are in general orchestrated by the sex genes at the A/ $P$ borders in the genital disc? The expression of RprREP and the low incidence of death at the A/P borders suggest that this may be the case. This would favor and order growth from the A/P borders with low competition, which should protect the majority of encells from death. In this sense, it is possible that the huge amount of endeath detected in the analias might be induced in a competitive manner by anterior cells and non-rprupregulated cells facing the segmental borders at the en cells.

It is interesting to ask to what extent the huge overgrowth of the A8 primordia represent the real contribution of death to normal growth? It may be in the males. In the females the overgrowth may reveal the relevance of cells death and the importance of its complete execution. The blockage of effector caspases may protect death target cells from proteolysis but it does not interfere with the other apoptosis-related process, known as the compensatory mechanism (Huh et al., 2004; Ryoo et al., 2004). It is this latter process which seems to be responsible in females for the increased amount of overgrowth due to directing P35 in dose dependent manner. Our experiments have shown that the JNK pathway is not necessary for inducing compensation (Ryoo et al., 2004), since increased growth was produced when JNK activation was blocked by over expressing Puc.

In summary, the present results demonstrate that JNK mechanisms, levels of pro-apoptotic factors and apoptosis participate in a relevant manner in regulating genital disc growth. We hope that these findings will contribute to advancing our understanding of how complex structures grow, as well as how altered growth due to deregulation of apoptosis affects tumors and malformations in other organisms.

\section{Materials and Methods}

\section{Genetics}

Oregon R. wild-type flies were used. Gene expression experiments were performed using the GAL4-UAS method (Brand and Perrimon, 1993). The principal drivers used were $A b d-B$-Gal4LDN, a Gal 4 insertion in the $A b d-$ $B$ menhancer (de Navas etal., 2006), and the cauda/Gal4 insertion (Calleja et al., 1996). Other drivers used were engrailedGal4 (Tabata et al., 1995) and puckered Gal4. The latter was used to monitor JNK activity in Drosophila, by examining expression of UAS-GFP directed by a Gal4 transgene inserted into the puckered (puc) gene (Pastor-Pareja et al., 2004). This is a JNK phosphatase which is part of a transcriptional negative feedback loop, since pucis a JNK negative regulator and simultaneously, a JNK target gene by means of its own promoter (Martín-Blanco et al., 1998); We refer to this reporter (puc-Gal4/UAS-Puc; UAS-GFP) simply as JNKREP. The UAS transgenes employed were UAS-P35 obtained from Bloomington Center; UAS DIAP1 (Ryoo et al., 2002); UAS-Puc (MartínBlanco et al., 1998); UAS-Bsk ${ }^{\mathrm{DN}}$ (dominant negative Basket, Drosophila JNK); UAS-HepCA (constitutively active Hemipterus, Drosophila JNKK) (Adachi-Yamada et al., 1999) and UAS-GFP (Ito et al., 1997).

For temporal activation of the UAS constructs, we performed stocks with a tubulin-Gal $80^{\mathrm{TS}}$ transgene(McGuire et al., 2003). Expression of reaper was revealed by an rpr-lacZ reporter gene fusion construct (Nordstrom et al., 1996), which is abbreviated as Rpr REP. hidA22 and Df (3L) H99 (DfH99) fly strains have previously been analyzed by Abbott and Lengyel (1991) and Grether et al. (1995).

\section{Antibodies and histochemistry}

The primary antibodies used were mouse anti-En from G. Morata; rabbit anti-Hid, a gift from Hermann Steller; rabbit anti-phosphohistone 3 (Cell Signaling Technology); rat anti-Caudal from G. Struhl; rabbit antiactive Caspase 3 (Cell Signaling Technology) and mouse anti- $\beta-G a$ (Promega). The secondary antibodies used for En detection was antimouse Alexa 594 and, for Caspase 3 and Phosphohistone 3 detection, anti-rabbit Cyo5 (Invitrogen). The protocol used is described in detail by Pérez-Garijo et al. (2004). For phase-contrast confocal imaging of adults, flies were dissected in PBS, fixed in 4\% paraformaldehyde for $20 \mathrm{~min}$, washed in PBS and mounted in Vectashield (Vector Labs).

\section{Image collection and processing}

Adults were observed with a Zeiss M 9.5 stereomicroscope, photographed with an adapted NIKON Coolpix 950 digital camera and processed with Adobe Photoshop software. The fluorescent images were obtained under a Zeiss confocal microscope in a multi-track session and processed with LSM 5 Image Browser and Adobe Photoshop software.

\section{Acknowledgements}

We wish to thank Ginés Morata and his collaborators, Ernesto SánchezHerrero and Susana Romani for their permanent support; E. SánchezHerrero for discussion and critical reading of the manuscript and also Noelia Roqué, an undergraduate student, for her help. Antibodies were generously received from $H$. Steller, G. Morata and A. Cáceres. Our thanks for flies to $H$. Steller and T. Adachi-Yamada. We thank the CIQUIBIC-INIMEC for confocal facilities and Carlos Mas and Sergio Dehner for technical assistance. This work has been supported in part by a grant from FONCYT and SECYT-UNC to Ana Macías. Nicolás Tomasini was supported by the Ministerio de Educación de la Nación Argentina and the Agencia Córdoba de Ciencia; Ana Macías is supported by CONICET.

\section{References}

ABRAMS, J.M. (1999). An emerging blueprint for apoptosis in Drosophila. Trends 
Cell Biol. 9: 435-440

ABBOTT, M.K. and LENGYEL, J.A. (1991). Embryonic head involution and rotation of male terminalia require the Drosophila locus head involution defective. Genetics 129: 783-789.

ADACHI-YAMADA, T., FUJIMURA-KAMADA, K., NISHIDA, Y. and MATSUMOTO, K. (1999). Distortion of proximo-distal information causes JNK-dependent apoptosis in Drosophila wing. Nature 400: 166-169.

AHMAD, S.M. and BAKER, B.S. (2002). Sex-Specific Deployment of FGF Signaling inn Drosophilarecruits mesodermal cells into the male genital imaginal disc. Cel/ 109: 651-661.

BRAND, A.H. and PERRIMON, N. (1993). Targeted gene expression as a means of altering cell fates and generating dominant phenotypes. Development 118: 401-415.

BERGMANN, A., AGAPITE, J., MCCALL, K. and STELLER, H. (1998). The Drosophila Gene hid is a direct molecular target of Ras-dependent survival signaling. Cel/95: 331-341.

CALLEJA, M., MORENO, E., PELAZ, S. and MORATA, G. (1996). Visualization of gene expression in living adult Drosophila. Science 274: 252-255.

CASARES, F., SÁNCHEZ L., GUERRERO, I. and SÁNCHEZ-HERRERO, E. (1997) The genital disc of Drosophila melanogaster. I. Segmental and compartmental organization. Dev Genes Evol207: 216-228.

CHAN, H.Y. and YANG, X. (2000). Proteases for Cell Suicide: Functions and Regulation of Caspases. Microbiol. Mol. Biol. Rev. 64:821-846.

CHEN, E.H., CHRISTIANSEN, A.E. and BAKER, B.S. (2005). Allocation and specification of the genital disc precursor cells in Drosophila. Dev. Biol. 281: 270-285

CHEN, P., NORDSTROM, W., GISH, B. and ABRAMS, J.M. (1996). grim, a nove cell death gene in Drosophila. Genes Dev. 10: 1773-1782.

de la COVA, C., ABRIL, M., BELLOSTA, P., GALLANT, P. and JOHNSTON, L.A. (2004). Drosophila mycregulates organ size by inducing cell competition. Cell 117: 107-116.

de NAVAS, L., FORONDA, D., SUZANNE, M. and SÁNCHEZ-HERRERO, E. (2006). A Simple and efficient method to identify replacements of $P$-lacZ by $P$ Gal4 lines allows obtaining Gal4 insertions in the Bithorax complex of Drosophila. Mech. Dev. 123: 860-867.

ESTRADA, B., CASARES, F. and SANCHEZ-HERRERO, E. (2003). Development of the genitalia in Drosophila melanogaster. Differentiation 71: 299-310.

GLEICHAUF, R. (1936). Anatomie und Variabilitat des Geschlechtapparates von Drosophila melanogaster(Meigen). Z. Wiss. Zoo/148: 1-66

GRETHER, M.E., ABRAMS, J.M., AGAPITE, J., WHITE, K. and STELLER, H. (1995). The head involution defective gene of Drosophila melanogasterfunctions in programmed cell death. Genes Dev. 9: 1694-1708.

HAY, B.A., WOLFF, T. and RUBIN, G.M. (1994). Expression of baculovirus P35 prevents cell death in Drosophila. Development 120: 2121-2129.

HAY, B.A. (2000). Understanding IAP function and regulation: a view from Drosophila. Cell Death Differ 7: 1045-1056.

HUH, J.R., GUO, M. and HAY, B.A. (2004). Compensatory proliferation induce by cell death in the Drosophila wing disc requires activity of the apical cell death caspase Dronc in a non-apoptotic role. Curr. Biol. 14: 1262-1266.

ITO, K., AWANO, W., SUZUKI, K., HIROMI, Y. and YAMAMOTO, D. (1997). The Drosophila mushroom body is a quadruple structure of clonal units each of which contains a virtually identical set of neurons and glial cells. Development 124: 761-771.

JIANG, C., BAEHRECKE, E.H. and THUMMEL, C.S. (1997). Steroid regulated programmed cell death during Drosophila metamorphosis. Development 124: 4673-4683.

KEISMAN, E.L., CHRISTIANSEN, A.E. and BAKER, B.S. (2001). The sex determination gene doublesex regulates the $A / P$ organizer to direct sex-specific patterns of growth in the Drosophila genital Imaginal Disc. Ce//1: 215-22.

KRIESER, R.J., MOORE, F.E., DRESNEK, D., PELLOCK, B.J., PATEL, R., HUANG, A., BRACHMANN, C. and WHITE, K. (2007). The Drosophila homolog of the putative phosphatidylserine receptor functions to inhibit apoptosis. Development 134: 2407-2414.

KURADA, P. and WHITE K. (1998). Ras promotes cell survival in Drosophila by downregulating hidexpression. Cel/95: 319-329.
KURANAGA, E., KANUKA, H., IGAKI, T., SAWAMOTO, K., ICHIJO, H., OKANO H. and MIURA, M. (2002). Reaper-mediated inhibition of DIAP1-induced DTRAF1 degradation results in activation of JNK in Drosophila. Nat. Cel/ Biol. 4: 705-710.

MACIAS, A., ROMERO, N.M., MARTIN, F.A., SUAREZ, L., ROSA, A.L. and MORATA, G. (2004). PVF1/PVR signaling and apoptosis promotes the rotation and dorsal closure of the Drosophila male terminalia. Int. J. Dev. Biol. 48: 10871094.

MARTíN, F.A., PERÉZ-GARIJO, A. and MORATA, G. (2009). Apoptosis in Drosophila: compensatory proliferation and undead cells. Int. J. Dev. Biol. 53: 1341 1347

MARTIN-BLANCO, E., GAMPEL, A., RING, J., VIRDEE, K., KIROV, N., TOLKOVSKY, A.M. and MARTINEZ-ARIAS, A. (1998). puckered encodes a phosphatase that mediates a feedback loop regulating JNK activity during dorsal closure in Drosophila. Genes Dev. 12: 557-570.

McCARTHY, J.V. (2003). Apoptosis and development. Essays Biochem. 39: 11-24.

McEWEN, D.G. and PEIFER, M. (2005). Puckered, a Drosophila MAPK phosphatase, ensures cell viability by antagonizing JNK-induced apoptosis. Deve/ opment 132: 3935-3946.

McGUIRE, S.E., LE, P.T., OSBORN, A.J., MATSUMOTO, K. and DAVIS, R.L. (2003). Spatiotemporal rescue of memory dysfunction in Drosophila. Science 302: 1765-1768.

MORATA, G. and RIPOLL, P. (1975). Minutes: mutants of Drosophila autonomously affecting cell division rate. Dev. Biol. 42: 211-221.

MORENO, E; BASLER, K. and MORATA G. (2002 a). Cells compete for Decapentaplegic survival factor to prevent apoptosis in Drosophila. Nature 416:755-759.

MORENO, E., YAN, M. and BASLER, K. (2002 b). Evolution of TNF signaling mechanisms: JNK-dependent apoptosis triggered by Eiger, the Drosophila homolog of the TNF superfamily. Curr. Biol. 12: 1263-1268.

MORENO, E. and BASLER, K. (2004). dMyc transforms cells into super-competitors. Cel/117: 117-129.

MURO, I., BERRY, D.L., HUH, J.R., CHEN, C.H., HUANG, H., YOO, S.J., GUO, M., BAEHRECKE, E.H. and HAY, B.A. (2006). The Drosophila caspase Ice is important for many apoptotic cell deaths and for spermatid individualization, a non-apoptotic process. Development 133: 3305-3315.

NORDSTROM, W., CHEN, P., STELLER, H. and ABRAMS, J.M. (1996). Activation of reaper Gene during Ectopic Cell Killing in Drosophila. Dev. Biol. 180: 213226.

PASTOR-PAREJA, J.C., GRAWE, F., MARTIN-BLANCO, E. and GARCIA-BELLIDO, A. (2004). Invasive cell behaviour during Drosophila imaginal disc eversion is mediated by the JNK signaling cascade. Dev. Cel/7: 387-399.

PEREZ-GARIJO, A., MARTIN, F.A. and MORATA, G. (2004). Caspase inhibition during apoptosis causes abnormal signaling and developmental aberrations in Drosophila. Development 131: 5591-5598.

PEREZ-GARIJO, A., MARTIN, F. A., STRUHL, G. and MORATA, G (2005). Dpp signaling and the induction of neoplastic tumours by caspase-inhibited apoptotic cells in Drosophila. Proc. Natl. Acad. Sci. USA 1002: 17664-17669.

POLASKI, S., WHITNEY, L., BARKER, B.W. and STRONACH, B. (2006). Genetic Analysis of Slipper/Mixed Lineage Kinase Reveals Requirements in Multiple Jun-N-Terminal Kinase-Dependent Morphogenetic Events During Drosophila Development. Genetics174: 719-733.

RYOO, H.D., BERGMANN, A., GONEN, H., CIECHANOVER, A. and STELLER, H. (2002). Regulation of DrosophilalAP1 degradation and apoptosis by reaperand ubcD1. Nat. Cell Biol. 4: 432-438.

RYOO, H.D., GORENC, T. and STELLER, H. (2004). Apoptotic cells can induce compensatory cell proliferation through the JNK and the Wingless signaling pathways. Dev. Cel/7: 491-501.

SANCHEZ, L. and GUERRERO, I. (2001). The development of the Drosophila genital disc. Bioessays 23: 698-707.

SPEDER, P. ADAM, G. and NOSELLI, S. (2006). Type ID unconventional myosin controls left-right asymmetry in Drosophila. Nature 440: 803-807.

SU, T.T., SPRENGER, F., DiGREGORIO, P.J., SHELAGH, D., CAMPBELL, S.D. and O'FARELL, P.H. (1998). Exit from mitosis in Drosophila syncytial embryos requires proteolysis and cyclin degradation, and is associated with localized dephosphorylation. Genes Dev. 12: 1495-1503.

TABATA, T., SCHWARTZ, C., GUSTAVSON, E., ALI, Z. and KORNBERG, T.B. 
(1995). Creating a Drosophila wing de novo, the role of engrailed and the compartment border hypothesis. Development 121: 3359-3369.

TSUJIMURA, H., YONEDA, T., AONUMA, H., ARAI, H. and HIRAI, S. (2008). Reaper- and Grim-induced cell death is suppressed by Ras/MAPK signaling in Drosophila developing indirect flight muscles. A. Dros. Res. Conf. 49: 764B.

WHITE, K.; TAHAOGLU, E. and STELLER, H. (1998). Cell Killing by the Drosophila Gene reaper. Science 271: 805-807.
XIA, Y. and KARIN, M. (2004). The control of cell motility and epithelial morphogenesis by Jun kinases. Trends Cell Biol. 14: 94-101.

YOO, J.S., HUH, J.R., MURO, I., YU, H., WANG, L., WANG, S.L., FELDMAN, R.M.R., CLEM, R.J., MÜLLER, H.A.J. and HAY, B.A. (2002). Hid, Rpr and Grim negatively regulate DIAP1 levels through distinct mechanisms. Nat. Cell Biol. 4:416-424.

\section{Further Related Reading, published previously in the Int. J. Dev. Biol.}

See Special Issue Pattern Formation edited by Michael K. Richardson and Cheng-Ming Chuong at: http://www.ijdb.ehu.es/web/contents.php?vol=53\&issue=5-6

Apoptosis in Drosophila: compensatory proliferation and undead cells Francisco A. Martín, Ainhoa Peréz-Garijo and Ginés Morata Int. J. Dev. Biol. (2009) 53:1341 - 1347

Origin and proliferation of blastema cells during regeneration of Drosophila wing imaginal discs

Manel Bosch, Jaume Baguñà and Florenci Serras

Int. J. Dev. Biol. (2008) 52: 1043-1050

Role of Jun N-terminal Kinase (JNK) signaling in the wound healing and regeneration of a Drosophila melanogaster wing imaginal disc

Jaakko Mattila, Leonid Omelyanchuk, Satu Kyttälä, Heikki Turunen and Seppo Nokkala Int. J. Dev. Biol. (2005) 49: 391-399

PVF1/PVR signaling and apoptosis promotes the rotation and dorsal closure of the Drosophila male terminalia

Ana Macías, Nuria M. Romero, Francisco Martín, Leonardo Suárez, Alberto L. Rosa and Ginés Morata

Int. J. Dev. Biol. (2004) 48: 1087-1094

Regulatory control of signal transduction during morphogenesis in Drosophila E Martín-Blanco

Int. J. Dev. Biol. (1998) 42: 363-368
5 yr ISI Impact Factor $(2008)=3.271$

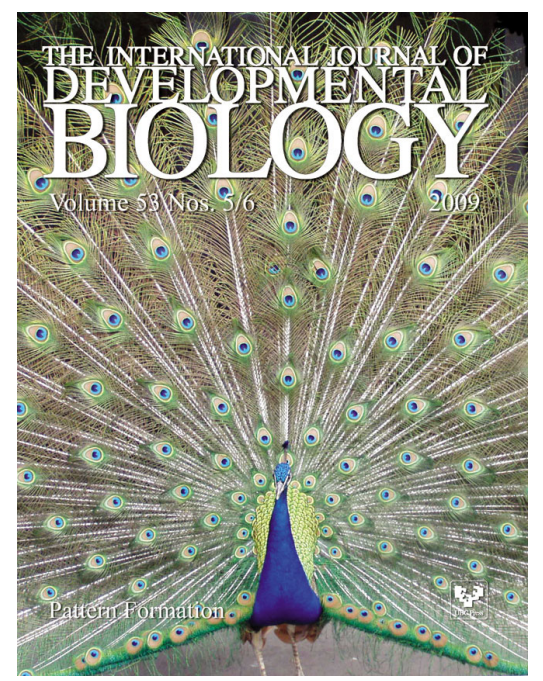

